\title{
O ACENTO NO PORTUGUÊS: O ESTUDO DE TRÊS PROCESSOS FONOLÓGICOS NA PRODUÇÃO DE FALANTES DO PORTUGUÊS BRASILEIRO $^{1}$
}

\author{
THE ACCENT IN PORTUGUESE: THE STUDY OF THREE PHONOLOGICAL \\ PROCESSES IN PRODUCTION OF BRAZILIAN PORTUGUESE SPEAKERS
}

\author{
Josa Coelho Irigoite \\ Doutoranda do Programa de Pós-graduação em Linguística - UFSC
}

\begin{abstract}
Resumo
Este artigo constitui-se em um estudo de três processos fonológicos cujas regras fazem referência ao acento no português: o apagamento da penúltima vogal nas proparoxítonas, transformando-as em paroxítonas; a desnasalização e a monotongação do ditongo final; e o alçamento das vogais médias. O objetivo é verificar a ocorrência dessas três regras na fala de duas falantes do português brasileiro, com base na Fonologia Gerativa. Os resultados mostram que tais processos fonológicos parecem ser influenciados ora por variáveis linguísticas - a posição em relação ao acento -, ora por variáveis sociais, como nível de escolaridade e região de origem.

Palavras-chave: Acento. Apagamento. Desnasalização. Fonologia Gerativa. Harmonia Vocálica. Monotongação.
\end{abstract}

\section{Abstract}

This article consists in a phonological study of three processes whose phonological rules refer to the accent in the portuguese: the deletion of the penultimate vowel in proparoxytone, turning them into paroxytone; the denasalization and the monophthongization of the final diphthong; and the raising of averages vowel. The objective is to check the occurrence of these three rules in the speak of two brazilian portuguese speakers, based on the Generative Phonology. The results show that such phonological processes appear to be influences sometimes by linguistic variables - the position in relation to accent - , sometimes by social variables as education level and region of origin.

Keywords: Accent. Deletion. Denasalization. Generative Phonology. Vowel Harmony. Monophtongization.

\section{INTRODUÇÃO}

Na primeira metade do século XX (1930), os estruturalistas definiram o fonema como portador de traços que o particularizam, uns pertinentes - os distintivos -, outros não, conforme apontam Oliveira e Brenner (1988). Câmara Júnior (2008) explica que os traços ditos distintivos são os que servem para distinguir uns sons vocais elementares dos outros, numa determinada língua. Com isso: “[...] cada fonema, ou seja, cada conjunto de certos traços distintivos opõe entre si as formas da língua, que o possuem,

\footnotetext{
${ }^{1}$ Trabalho para disciplina de Fonologia, ministrada no $1^{\circ}$ semestre de 2011, sob orientação da professora Dr. ${ }^{a}$ Teresinha de Moraes Brenner.
} 
em face de outras formas, que não o possuem, ou possuem em seu lugar outro fonema" (CÂMARA JÚNIOR, 2008, p. 33). Lepschy (1975) ressalta que o fonema é composto de várias particularidades, de vários traços, mas se distingue de outro fonema não por todos os traços, mas por alguns deles. $\mathrm{O}$ fonema /d/, por exemplo, teria os seguintes traços distintivos:

$$
\begin{aligned}
& \text { (1) } / \mathrm{d} / \\
& {\left[\begin{array}{l}
+ \text { consoante } \\
+ \text { sonoro } \\
+ \text { alveolar } \\
+ \text { oral }
\end{array}\right]}
\end{aligned}
$$

Se substituirmos o traço [+oral] pelo traço [+nasal], altera-se o fonema e obtém-se /n/ neste caso, $/ \mathrm{d} / \mathrm{e} / \mathrm{n} /$ são fonemas porque a comutação entre eles altera o significado do signo linguístico (nado x dado). Temos, assim, várias oposições fonológicas distintivas organizadas em sistema.

Mas, quando chegamos ao estudo do acento, não há consenso se se trata de um fonema da língua, ou seja, se há contraste nas palavras que se distinguem apenas pela posição do acento, ou não. Por exemplo, as palavras sabia e sabiá: nesse caso, a posição do acento altera o significado. Muitos autores, assim, consideram o acento como fonema, mas de um tipo especial, que se superpõe aos segmentos, ao invés de ser colocado linearmente entre eles. Neste caso, o acento é denominado de supra-segmento, conforme aponta Collischonn (1999).

Como não é possível prever a posição do acento, Collischonn (1999, p. 133) o considera como "uma informação idiossincrática" a respeito da palavra, que deve ser memorizada pelo falante. Por outro lado, conforme aponta a própria autora, não se pode negar a existência de uma série de regularidades que há por trás da distribuição do acento, como, por exemplo, o fato de que o acento somente pode recair sobre uma das três últimas sílabas, regra que se aplica no português, no espanhol e no latim. Essa é uma propriedade distributiva do acento na nossa língua, que faz com que tenhamos apenas palavras oxítonas, paroxítonas e proparoxítonas. A autora também aponta mais duas regularidades do acento em português brasileiro: a posição do acento na penúltima sílaba é a preferida quando a palavra for terminada em vogal; a posição do acento sobre a última sílaba é a preferida quando a palavra for terminada em consoante.

Diante desses pequenos exemplos, já podemos concluir que a distribuição do acento, inclusive no português, não é aleatória, mas segue regras fonológicas que regem fenômenos da nossa língua. E essas regularidades precisam ser explicadas por qualquer modelo de descrição do acento. Collischonn (1999) apresenta alguns exemplos de trabalhos que analisam o acento no português, em dois modelos diferentes: a Fonologia Gerativa e a Geometria dos Traços.

Este artigo escolheu três fenômenos cujas regras fonológicas fazem referência ao acento no português, analisando qualitativamente a ocorrência desses fenômenos na produção de duas falantes do português e seguindo o modelo da Fonologia Gerativa. São eles: 
(2)

(a) Apagamento da penúltima vogal nas proparoxítonas, transformando-as em paroxítonas: essa é um tipo de regra que, segundo Collischonn (1999), muda um padrão marcado de acento para um padrão não-marcado. Exemplo: abóbora > abóbra.

(b) Desnasalização e monotongação do ditongo final: trata-se de outra regra que torna um padrão marcado - paroxítonas - em um padrão não-marcado. Exemplos: hom[ẽj] > hom[i]; móv[ej]s>móv[i]s.

(c) Alçamento das vogais médias ou elevação vocálica: quando uma vogal média alta - /e,o/ - torna-se média baixa - / $\varepsilon, \mathrm{o} /$.

Cada uma dessas regras será detalhada a seguir para, posteriormente, serem analisadas na fala das duas informantes selecionadas para este artigo. Mas, antes, veremos pequenos exemplos de análises e regras propostas pela Fonologia Gerativa em relação ao acento na língua portuguesa.

\section{O ACENTO NO PORTUGUÊS E A PROPOSTA DA FONOLOGIA GERATIVA}

Na seção anterior, foram apontadas algumas regularidades do acento no português, que corroboram a hipótese de que há regras fonológicas que regem a posição do acento nas palavras. Collischonn (1999) levanta outras características sobre o acento no português, como o fato de que a maioria das palavras são paroxítonas. Segundo a autora, as propaxorítonas são consideradas esdrúxulas na nossa língua, sendo essa característica marcada pela regra de que toda proparoxítona deve ser escrita com acento gráfico. As proparoxítonas são empréstimos do latim e do grego e, por essa razão, há uma tendência na fala a regularizar o acento para a posição paroxítona, com o apagamento da penúltima vogal, conforme os exemplos de Collischonn (1999, p. 133) ${ }^{2}$ :

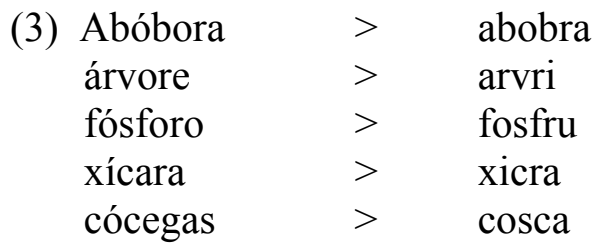

Já as oxítonas, segundo a autora, são mais frequentes do que as proparoxítonas. Há o grupo das que possuem consoante final - sol, dançar, juiz - e o grupo das que terminam com vogal - acarajé, baú, urubu. A autora afirma que há uma preferência por parte do acento pela última sílaba quando esta é terminada por consoante: $78 \%$ das palavras terminadas em consoante são oxítonas, enquanto apenas $22 \%$ dessas palavras são paroxítonas. Quando a palavra, assim, for terminada por consoante, o acento marcado ou seja, que recebe o acento gráfico - é o paroxítono e o menos marcado é o oxítono. Vejamos os exemplos trazidos pela autora (COLLISCHONN, 1999, p. 134) - a coluna

\footnotetext{
${ }^{2}$ A numeração dos exemplos não segue a do texto original de Collischonn (1999), mas a deste artigo.
} 
(a) traz palavras oxítonas terminadas em consoante que não recebem acento, e a coluna

(b) apresenta paroxítonas terminadas em consoante que são acentuadas graficamente:

$\begin{array}{cc}\text { (4) a) sugar } & \text { b) açúcar } \\ \text { colher } & \text { cadáver } \\ \text { vigor } & \text { Vítor } \\ \text { cordel } & \text { móvel } \\ \text { civil } & \text { fácil }\end{array}$

Por outro lado, Collischonn (1999, p. 134) aponta que o grupo de palavras oxítonas terminadas por vogal é pequeno e, na maioria, são empréstimos do francês, línguas indígenas e africanas, como nos exemplos abaixo:

(5) a) avó, bocó, fuzuê

b) sofá, café, crochê

c) aracá, jacaré, urubu

d) xangô, banzé

Há uma preferência do acento, portanto, pela posição paroxítona em palavras terminadas em vogal (normalmente a, e, o) que, por essa razão, são consideradas não marcadas - não levam acento gráfico. As outras posições em relação a esta são consideradas marcadas, ou seja, acentuadas graficamente. A autora finaliza esse levantamento de regularidades do acento no português afirmando ainda que, em palavras terminadas em consoante, o acento cai preferencialmente sobre a última sílaba.

A partir dessas e de outras regularidades, muitos autores, com base na Fonologia Gerativa, propuseram análises para o acento em português, formulando regras que abarcassem todos os processos fonológicos possíveis. Collischonn (1999) traz alguns exemplos de autores e suas respectivas regras, como por exemplo Mateus, que propôs duas análises para o acento, em 1975 e em 1983. Na primeira análise, segundo Collischonn (1999, p. 139), Mateus formula como regra geral:

(6) Regra geral de acentuação

$$
\mathrm{V} \rightarrow[+ \text { acento }] / \ldots(\mathrm{G}) \mathrm{C}_{\mathrm{o}} \mathrm{V} \mathrm{C}_{\mathrm{o}} \#
$$

$\mathrm{Na}$ regra (6), ' $\mathrm{G}$ ' significa glide e ' $\mathrm{C}_{\mathrm{o}}$ ' significa "uma, mais de uma ou nenhuma consoante". Transcrevendo a regra, temos: uma vogal receberá acento no contexto em que ocupa a posição da penúltima vogal, seguida ou não de glide. Entre a última e a penúltima vogal, pode haver uma consoante (fita, dedo); duas consoantes (festa, porta); ou nenhuma consoante (boa). Pode haver também uma semivogal (saia, freio); ou uma semivogal mais uma consoante (caule, moita). Mateus (1983, apud COLLISCHONN, 1999, p. 139) também apresenta uma regra para as proparoxítonas - em (7) - e outra para as oxítonas - em (8) -, nas quais ' $+E$ ' e ' $+\mathrm{A}$ ' são diacríticos que marcam, na representação subjacente, as palavras proparoxítonas (esdrúxulas) e as oxítonas (agudas), respectivamente:

(7) Regra de acentuação das proparoxítonas

$$
\left(\begin{array}{c}
\mathrm{V} \\
+\mathrm{E}
\end{array}\right] \rightarrow[+\mathrm{ac}] /\left[{ }_{-}\right] \mathrm{C}_{\mathrm{o}} \mathrm{V} \mathrm{C}_{\mathrm{o}} \mathrm{V} \mathrm{C}_{\mathrm{o}} \#
$$


(8) Regra de acentuação das oxítonas

$$
\left(\begin{array}{r}
\mathrm{V} \\
+\mathrm{A}
\end{array}\right] \rightarrow[+\mathrm{ac}] /\left[\mathrm{C}_{\mathrm{o}} \#\right.
$$

Na segunda análise, apontada por Mateus (1983, apud COLLISCHONN, 1999, p. 140), a autora leva em conta a estrutura morfológica da palavra: a regra (9) estabelece que o acento seja atribuído à vogal mais à direita do radical, sendo que, nos verbos, será atribuído à vogal temática. Eis a regra de Mateus (1983, apud COLLISCHONN, 1999):

$$
\begin{array}{lll}
\text { (9) fa'la+r } & \text { fa'la+va } & \text { fa'la+va+mos } \\
\text { ba'te+u } & \text { ba'te+ra } & \text { ba'te+sse+mos } \\
\text { par'ti }+u & \text { par'ti+ra } & \text { par'ti }+ \text { sse }+ \text { mos }
\end{array}
$$

Outra autora que propõe uma análise do acento semelhante à de Mateus é Lopez (1979, apud COLLISCHONN, 1999, p.140):

(10) Regra geral de acento

$$
\left.\mathrm{V} \rightarrow[+ \text { acento }] / \ldots \mathrm{C}_{\mathrm{o}}\right]_{\text {radical }}
$$

Não se considerarão, aqui, exceções a essas regras, nem as críticas que a própria Collischonn (1999) faz a essas propostas de análise. O objetivo é exemplificar o tipo de trabalho que a Fonologia Gerativa fez/está fazendo sobre o acento no português: ela se propõe a formalizar as oposições e distribuições presentes nos sistemas sonoros através de regras fonológicas, o que inclui o traço supra-segmental do acento. A seguir, apresentam-se as regras fonológicas que dizem respeito aos três fenômenos estudados neste artigo: apagamento da penúltima vogal nas proparoxítonas; desnasalização e monotongação do ditongo; e alçamento das vogais médias.

\section{O PROCESSO DE APAGAMENTO DA PENÚLTIMA VOGAL NAS PROPAROXÍTONAS}

Conforme mencionado por Collischonn (1999), o grupo das proparoxítonas é o menor em português. Esse grupo, segundo a autora, incluiu sobretudo empréstimos do latim e do grego, que entraram na língua portuguesa a partir do período da Renascença, quando escritores, artistas e estudiosos em geral passaram a se interessar significativamente pelo período clássico. Como evidência do caráter não nativo dessas palavras, Collischonn (1999, p. 133) aponta para a tendência dos falantes brasileiros a regularizar o acento para a posição paroxítona - grande prevalência no português brasileiro -, através do apagamento da penúltima sílaba, como nos exemplos em (11). A autora, assim, considera o acento proparoxítono como "menos usual", um acento especial contrário à tendência geral de acentuar a penúltima sílaba.

$\begin{array}{lll}\text { (11) abóbora } & < & \text { abobra } \\ \text { árvore } & < & \text { arvri } \\ \text { fósforo } & < & \text { fosfru } \\ \text { xícara } & < & \text { xicra } \\ \text { cócegas } & < & \text { cosca }\end{array}$


Trata-se de um processo fonológico, ou seja, uma alteração sonora sofrida nas formas básicas dos morfemas quando se combinam para formar palavras ou no início ou final de palavras justapostas (SCHANE, 1975), no qual um sistema de regras relaciona a estrutura profunda de um item lexical à sua estrutura fonética. Assim, quando a penúltima vogal desaparece, transformando uma proparoxítona em paroxítona, ocorre uma síncope, pois uma vogal próxima a uma outra acentuada é eliminada.

Já Cagliari (2002) classifica esse processo como eliminação (podendo também ser denominado apagamento, queda, truncamento), definindo-o como supressão de um segmento da forma básica de um morfema. O autor explica ainda que os processos fonológicos são regidos por regras cíclicas. Vejamos o exemplo da palavra 'âncora' e as regras que causam o apagamento facultativo da postônica:

(12) Apagamento facultativo em 'âncora'

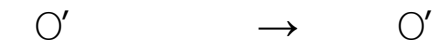

a) Regra de acentuação da proparoxítona

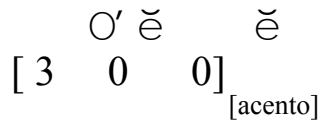

b) Apagamento da vogal pós-tônica

$$
\begin{aligned}
& \text { Regra: } \mathrm{V} \rightarrow \varnothing / \mathrm{V}^{\mathrm{c}} \text {. C _. CV } \\
& {[[0] \quad[3][0] \quad[0]]}
\end{aligned}
$$

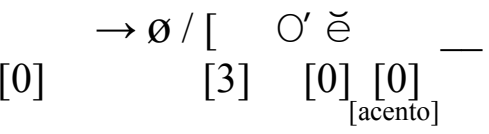

c) Ressilabação à direita

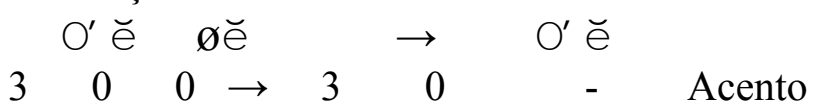

Seja:

VC. Cø. CV $\rightarrow$ V.CCV

\section{OS PROCESSOS DE DESNASALIZAÇÃO E MONOTONGAÇÃO DO DITONGO}

Segundo Silva (2002), os ditongos são tratados como uma sequência de segmentos, na qual um dos segmentos é interpretado como uma vogal e o outro é interpretado como glide - vogais sem proeminência acentual nos ditongos. A autora aponta ainda os dois tipos de ditongos, denominados respectivamente de crescente e de decrescente. Os primeiros apresentam proeminência acentual na segunda vogal e uma sequência de glide-vogal, como no exemplo em [3uílzadu]. Já nos ditongos decrescentes, a proeminência acentual ocorre na primeira vogal e tem-se uma sequência de vogal-glide, como em [paunlade]. 
Um dos fenômenos linguísticos que se encontram em variação no português brasileiro denomina-se monotongação e consiste no apagamento do glide em ditongos orais decrescentes. Quando o ditongo é nasal, o processo de redução é denominado de desnasalização. Collinschonn (1999, p. 138) apresenta exemplos de desnasalização (13.a) e monotongação (13.b):

$$
\begin{aligned}
& \text { a) hom[ẽj] } \rightarrow \operatorname{hom}[\mathrm{i}] \\
& \text { órf[ãw] } \rightarrow \text { órf[u] } \\
& \operatorname{viag}[\tilde{\mathrm{ej}}] \quad \rightarrow \quad \operatorname{viag}[\mathrm{i}] \\
& \text { falar[ãw] ( } 3^{\mathrm{a}} \text { p. pl. pret. perf.: falaram) } \rightarrow \text { falar[u] } \\
& \text { b) móv[ej]s } \rightarrow \text { móv[i]s } \\
& \text { jérs[ej] } \rightarrow \text { jérs[i] } \\
& \text { vôl[ej] } \rightarrow \text { vôl[i] }
\end{aligned}
$$

Ambos os processos são exemplos da regra apontada por Collinschonn (1999) que muda um padrão marcado de acento em uma padrão não-marcado; neste caso, tornam paroxítonas marcadas em não-marcadas, como nos exemplos em (13). Silva (2004) explica que a tendência ao enfraquecimento do segundo elemento surgiu nas línguas derivadas (latim, grego e línguas românicas em geral), transformando-se em ditongos breves ou simples vogais, seguindo o curso das mudanças linguísticas. Os ditongos, assim, modificaram-se na passagem do latim para o português brasileiro, por isso o fato de que os processos de assimilação ou monotongação que reduzem os ditongos a uma única vogal são constantes na nossa língua.

O processo de redução do ditongo que ocorre pelo "cancelamento do glide", segundo Silva (2003, p. 59), pode se generalizar, tendo motivação semelhante para ambos os ditongos [eI] e [ou ], tendo, assim, mais poder explanatório. A autora formaliza a seguinte regra fonológica para expressar o processo de cancelamento de glide ${ }^{3}$ :

\begin{tabular}{|c|c|c|c|c|}
\hline (15) & feira & ['feirre] & $\sim$ & ['feñre] \\
\hline & queixa & ['keI $\left.\int e\right]$ & $\sim$ & ['ke $\left.\int e\right]$ \\
\hline & beirada & [beI'rade] & $\sim$ & [be'rade] \\
\hline & queijo & ['keIzul] & $\sim$ & ['kezu] \\
\hline & desejo & [de'zeIzu] & $\sim$ & [de'zez \\
\hline & touro & ['tounru] & $\sim$ & ['torv] \\
\hline & dourada & [doun'rade] & $\sim$ & [do'rade] \\
\hline & outro & ['outru] & $\sim$ & ['otru] \\
\hline
\end{tabular}

$$
\underset{\mathrm{I}, U}{\longrightarrow} \rightarrow \varnothing / \mathrm{e}, \mathrm{o}
$$

Na regra (14), assim, temos: um glide é cancelado quando antecedido de vogal média correspondente se ele se encontrar em final de sílaba. A autora (2003, p. 58) também aponta exemplos de redução do ditongo que não ocorre no final de sílaba, mas antecedendo a uma consoante:

\footnotetext{
${ }^{3}$ O símbolo \$ é usado por Silva (2003) para designar final de sílaba.
} 
Para esses casos, Andrade (1994, p. 11) formula a seguinte regra referente à transformação /éjC/ $\rightarrow$ /éøC/, na qual acrescentamos as informações para o cancelamento do glide /w/ no ditongo /ow/:

$$
\mathrm{j}, \mathrm{w} \rightarrow \varnothing / \mathrm{e}, \mathrm{o} \_\mathrm{C}
$$

Semelhante à regra (14), em (16), temos que um glide é cancelado quando antecedido da vogal média correspondente se ele se encontrar antes de uma consoante. Silva aponta que os segmentos [eI, e] e [ou, o] são considerados classes naturais, pelo fato de um segmento ser convertido em outro segmento por uma regra fonológica.

Por outro lado, há palavras que não aceitam a redução do ditongo, como nos exemplos a seguir, apontados por Silva $\left(2003\right.$, p. 59) ${ }^{4}$ :

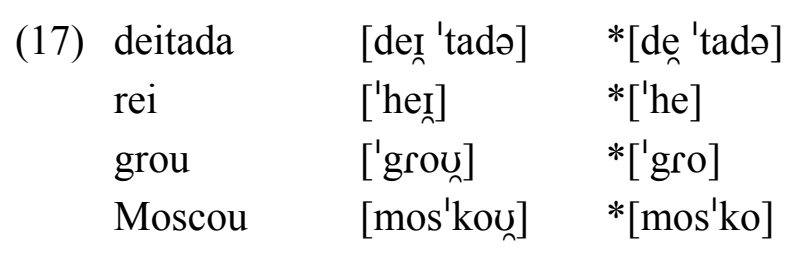

Conforme explica a autora, devemos recordar que a Fonologia Gerativa define certas regras como categóricas, ou seja, que se aplicam sempre que o contexto é encontrado, por isso são regras obrigatórias. Neste caso, não há formas alternantes em competição (variação linguística) e o processo fonológico se aplica sempre que o contexto é encontrado. Em contrapartida, há as regras opcionais, que podem ser aplicadas ou não, tendo-se formas concorrentes (duas pronúncias possíveis para uma mesma palavra). $\mathrm{O}$ mecanismo proposto pelo modelo Gerativo, assim, pode somente estipular que, em certos casos, as regras se aplicam incondicionalmente (obrigatórias) e em outros casos a aplicação é opcional. Concluímos, portanto, que o processo de cancelamento do glide em ditongo é uma regra opcional, pois não se aplica em todos os contextos.

Em pesquisa sobre o processo de monotongação em João Pessoa, Silva (2004) levantou a hipótese de que as vibrantes e as fricativas são mais favoráveis à redução do ditongo, por compartilhamento de traços similares que conduzem ao processo de assimilação. Os resultados da autora mostram que o ditongo [aj] está sujeito a sofrer redução quando se encontra em sílaba pretônica (como em 'abaixar'), enquanto as sílabas tônicas inibem o processo ('baixo'). A monotongação do ditongo [ej] também é mais frequente na sílaba pretônica. Já, em palavras com o ditongo [ow], encontra-se a monotongação favorecida em sílabas tônicas.

\section{O PROCESSO DE ALÇAMENTO DAS VOGAIS MÉDIAS NA POSIÇÃO PRETÔNICA}

Conforme explica Silva (2004), a fonologia Gerativa faz uso da nomenclatura segmento fonológico para indicar um som que tenha caráter distintivo em relação aos outros. $\mathrm{O}$

\footnotetext{
${ }^{4}$ Os asteriscos indicam formas que não ocorrem na língua portuguesa, por isso são consideradas "agramaticais".
} 
português brasileiro possui os segmentos fonológicos /e, $\varepsilon, \mathrm{o}, \mathrm{o} /$ que ocorrem em sílaba tônica em todos os dialetos, com grande variação quando se encontram em posição pretônica. Essa variação é apontada por Collischonn (1999) como um exemplo de regra que precisa da aplicação prévia do acento para poder se referir às vogais tônicas. Temos como exemplo dessa regra a elevação das vogais médias quando elas estão em sílaba fechada por oclusiva $(\sin [0] p s e, s[\varepsilon] x o)$, restrita à posição tônica $(s[\varepsilon] x o-s[e] x u a l)$. Trata-se, portanto, de uma regra que necessita da informação sobre o acento para ser aplicada ou não.

Podemos considerar esse processo como um tipo especial de assimilação, denominado harmonia vocálica. Cagliari (2002) explica que a harmonia vocálica faz com que vogais se tornem semelhantes entre si, geralmente por alguma razão morfológica (regra morfofonológica). Por exemplo, as vogais da palavra 'menino' se assemelham quando as médias se elevam transformando-se em altas, como em [mi'ninu]. Silva (2003, p. 65) apresenta essa assimilação comparando exemplos de palavras simples e derivadas, nas quais uma vogal média aberta $-\varepsilon$,$\lrcorner - ocorre como uma vogal média fechada - e, o -$ quando em posição tônica:

\begin{tabular}{|c|c|c|c|c|}
\hline \multicolumn{2}{|c|}{ Base } & & \multicolumn{2}{|c|}{ Derivada } \\
\hline terra & ['teRp] & $\mathrm{X}$ & terráqueo & [te'Rakınu] \\
\hline sola & ['sole] & $\mathrm{x}$ & solado & [so'ladu] \\
\hline bela & ['bele] & $\mathrm{X}$ & beleza & [be'leze] \\
\hline roça & ['hose] & $\mathrm{x}$ & roçado & [ho'sadu] \\
\hline
\end{tabular}

Pode-se observar, como frisa a autora, que, quando a vogal média ocorre em posição tônica, temos uma vogal aberta $-\varepsilon, \rho-e$, nas palavras derivadas, temos uma vogal média fechada - e, o - que ocorre em posição pretônica. Novamente trata-se de uma regra opcional, pois há exemplos de palavras derivadas que apresentam uma vogal média aberta $-\varepsilon, \supset-$ em posição pretônica (SILVA, 2003, p. 66):

\begin{tabular}{|c|c|c|}
\hline (19) & terrestre & [t $\left.\varepsilon^{\prime} \operatorname{RestrI}\right]$ \\
\hline & bolota & [bo'lote] \\
\hline & solinha & [so'Tiỹe] \\
\hline & belíssimo & [be'lisimu] \\
\hline
\end{tabular}

Ao tentar apontar alguns fatores que condicionam a ocorrência de vogais pretônicas médias abertas e de médias fechadas nas palavras derivadas, Silva (2003) aponta para duas características das derivadas que apresentam uma vogal média aberta: o sufixo derivacional apresenta uma vogal média aberta $\varepsilon$, o ou um dos sufixos -inh, -zinh, íssim, -ment ocorre. Palavras com outros sufixos devem apresentar vogal média fechada em posição pretônica.

A ocorrência de uma vogal média aberta em posição tônica e de outra vogal aberta em posição pretônica também ocorre em palavras não derivadas, como nos exemplos de Silva (2003, p. 67): 


\begin{tabular}{|c|c|}
\hline comédia & 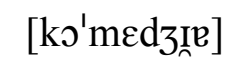 \\
\hline peteca & [p $\left.\varepsilon^{\prime} t \varepsilon k e\right]$ \\
\hline colega & [ko'lege] \\
\hline xodó & [ $\left.\rho^{\prime} \mathrm{d} \rho\right]$ \\
\hline Pelé & {$\left[p \varepsilon^{\prime} 1 \varepsilon\right]$} \\
\hline bocó & [bo'ko] \\
\hline serelepe & [sere'lepi] \\
\hline pororoca & [рого'roke] \\
\hline remoto & {$\left[\mathrm{R} \varepsilon^{\prime} \mathrm{m} \mathrm{t}_{\mathrm{t}}\right]$} \\
\hline
\end{tabular}

A autora alerta para o fato de que, nesses exemplos, as vogais devem ser médiasabertas, não necessariamente idênticas quanto à anterioridade ou posterioridade - por isso pode-se ter as combinações $\varepsilon \supset$ e $ə \varepsilon$. Pode-se observar também a possibilidade de ocorrência de mais de duas vogais médias na palavra, desde que elas mantenham sistematicamente o grau de abertura (serem médias abertas).

Processo de harmonia vocálica também ocorre com as vogais médias anteriores e posteriores; ou seja, neste caso também a vogal pretônica concorda com a vogal tônica da palavra quanto ao grau de abertura (se é média-alta ou média-baixa / média-aberta ou média-fechada), conforme os exemplos em (21), também de Silva (2003, p. 68):

\begin{tabular}{|c|c|}
\hline reboco & [Re'bokv] \\
\hline colosso & [ko'losv] \\
\hline cereja & [se'reze] \\
\hline proeza & [pro'eze] \\
\hline
\end{tabular}

A partir de todos esses exemplos, Silva (2003, p. 69) formula a seguinte regra:

(22) $[$-acento $] \rightarrow[\alpha$ baixo $] /$

$$
\overline{\left(\begin{array}{c}
+ \text { acento } \\
\text { abaixo }^{5}
\end{array}\right)}
$$

Em (22), temos: uma vogal não-acentuada assume o mesmo valor do traço [baixo] da vogal acentuada. Assim, se a vogal tônica tiver o traço [+baixo], a vogal pretônica também terá o traço [+baixo], da mesma forma que se tiver o traço [-baixo], a pretônica também terá o traço [-baixo].

\section{PROCEDIMENTOS METODOLÓGICOS DA PESQUISA}

Os processos fonológicos descritos anteriormente foram investigados na fala de duas informantes do sexo feminino, ambas residentes na cidade de Florianópolis, mas nascidas em regiões diferentes. Como variáveis sociais, foram considerados a região de origem e o nível de escolaridade. A Informante 1 nasceu em São Miguel do Oeste

\footnotetext{
${ }^{5} \mathrm{O}$ símbolo $\alpha$ significa + ou -; ou seja, indica que o mesmo valor para o traço em questão deverá ser assumido.
} 
(Santa Catarina), possui 47 anos e tem nível superior completo. Já a Informante 2 nasceu em Carazinho (Rio Grande do Sul), tem 59 anos e não completou o ensino médio. Todas essas informações foram consideradas como fatores sociais envolvidos nas análises dos dados, além dos fatores linguísticos baseados nos estudos citados anteriormente.

O estudo foi feito a partir de entrevista oral gravada, a qual se dividiu em duas etapas: iniciou-se com perguntas com respostas livres, seguida da leitura de 15 frases dirigidas que abarcaram exemplos dos processos fonológicos estudados. No Anexo I, apresentase o corpus de análise.

\section{ANÁLISE DOS DADOS}

Em relação ao primeiro processo estudado, o apagamento da penúltima vogal das proparoxítonas, totalizaram-se 7 ocorrências de proparoxítonas nas produções das duas informantes. A Informante 1 manteve 6 proparoxítonas, transformando apenas $1 \mathrm{em}$ paroxítona: a palavra 'Florianópolis' que foi pronunciada [florie'nopis]. Já a Informante 2 obteve um resultado oposto: manteve apenas 1 proparoxítona, transformando as outras 6 em paroxítonas, pelo apagamento da penúltima vogal. Vejamos os exemplos em questão da Informante 2:

\begin{tabular}{|c|c|c|}
\hline (23) & Florianópolis & [florie'nopis] \\
\hline & fósforo & ['fosfru] \\
\hline & árvore & ['arveri] \\
\hline & xícara & ['Jikre] \\
\hline & abóbora & [e'bobre] \\
\hline & brócolis & ['blokus] \\
\hline
\end{tabular}

A hipótese que se constrói aqui é que esse processo de apagamento parece influenciado pela escolaridade, dado que, nas produções da informante menos escolarizada, a Informante 2, percebeu-se uma visível dificuldade ao pronunciar e até ao ler palavras proparoxítonas. A única palavra que não apresentou apagamento de vogal na fala da Informante 2 foi 'frigorífico', cuja explicação pode ser a familiaridade que a informante possui com a palavra, que designa o local onde seu marido trabalha.

Em relação ao segundo fenômeno - desnasalização e monotongação do ditongo -, os resultados são mais complexos, pois as variantes são diversas e dependem de variáveis distintas, como, por exemplo, o contexto linguístico. Houve um total de 74 ocorrências de ditongos decrescentes na fala da Informante 1 e 68 na da Informante 2. Desse total, selecionaram-se apenas os casos que interessam ao foco deste artigo - o desaparecimento ou não do glide - e que estão apresentados na tabela a seguir:

Tabela 1. Porcentagem do apagamento do glide segundo contextos linguísticos.

\begin{tabular}{|c|c|c|c|c|c|}
\hline \multirow{2}{*}{ DITONGO } & \multirow{2}{*}{ CONTEXTO } & \multicolumn{2}{|c|}{ OCORRÊNCIA / TOTAL } & \multicolumn{2}{c|}{ PORCENTAGEM } \\
\cline { 3 - 6 } & & Informante 1 & Informante 2 & Informante 1 & Informante 2 \\
\hline \multirow{2}{*}{ /eu/ } & Monossílabos & $0 / 15$ & $0 / 19$ & $\mathbf{0 \%}$ & $\mathbf{0 \%}$ \\
\cline { 2 - 6 } & Oxítonas & $0 / 2$ & - & $\mathbf{0 \%}$ & - \\
\hline
\end{tabular}




\begin{tabular}{|c|c|c|c|c|c|}
\hline \multirow{2}{*}{$/ \mathrm{eI} /$} & Posição tônica & $0 / 2$ & $0 / 6$ & $\mathbf{0 \%}$ & 0\% \\
\hline & $\begin{array}{c}\text { Posição } \\
\text { postônica }\end{array}$ & $0 / 2$ & $2 / 2$ & $\mathbf{0 \%}$ & $100 \%$ \\
\hline \multirow{3}{*}{ /ẽ I/ } & Monossílabos & $0 / 11$ & $0 / 4$ & 0\% & $0 \%$ \\
\hline & Posição tônica & $0 / 2$ & $0 / 4$ & $\mathbf{0 \%}$ & $0 \%$ \\
\hline & $\begin{array}{l}\text { Posição } \\
\text { postônica }\end{array}$ & $0 / 4$ & $3 / 3$ & 0\% & $100 \%$ \\
\hline \multirow{3}{*}{ /ãv/ } & Monossílabos & $0 / 13$ & $0 / 3$ & 0\% & $0 \%$ \\
\hline & Posição tônica & $0 / 5$ & $0 / 5$ & $\mathbf{0 \%}$ & $0 \%$ \\
\hline & $\begin{array}{l}\text { Posição } \\
\text { postônica }\end{array}$ & $3 / 4$ & $0 / 2$ & $75 \%$ & $0 \%$ \\
\hline /õu/ & Monossílabos & $0 / 3$ & $0 / 3$ & 0\% & $0 \%$ \\
\hline /ou/ & Posição tônica & - & $4 / 4$ & - & $100 \%$ \\
\hline
\end{tabular}

Fonte: construção da autora.

O primeiro ponto visível nesses resultados é que a redução do ditongo ocorre mais em contextos específicos, por isso o número é tão reduzido. Pode-se concluir, por exemplo, que em monossílabos tônicos (eu, meu, tem, bem, são, não, bom) não há apagamento do glide em quaisquer ditongos. Já nas palavras com duas ou mais sílabas, o que influencia o apagamento ou não é a posição do ditongo de acordo com o acento - posição tônica ou posição postônica. Por exemplo, tanto nos ditongos /eI/ quanto /ẽI/, há a redução nos casos em que o ditongo ocupa a posição postônica. Vejamos essas ocorrências na fala da Informante 2:

\begin{tabular}{|c|c|c|}
\hline (24) & enfermagem & {$\left[\tilde{\mathrm{e}}^{\mathrm{n}}\right.$ fer $\left.^{\prime} \mathrm{ma} \mathrm{I} \mathrm{I}\right]$} \\
\hline & homem & ['omI] \\
\hline & viagem & [vi'azI] \\
\hline & vôlei & ['voli] \\
\hline
\end{tabular}

No caso do ditongo /el/, além de depender da posição em relação ao acento, percebe-se que sua redução apareceu apenas na fala da Informante 2, o que pode sinalizar relação com a baixa escolaridade da informante. Vejamos o que temos como resultados referentes ao ditongo /ãư/.

Com o ditongo /ãơ/, além da posição em relação ao acento - novamente há redução do ditongo apenas quando este ocupa a posição postônica -, o morfema flexional também influencia a ocorrência ou não dessa regra. Em todas as 3 ocorrências na fala da Informante 1, o ditongo fazia parte das desinências modo-temporal e número-pessoal de verbos na terceira pessoa do plural, no pretérito perfeito do indicativo; ou seja, na forma -ram. Eis os exemplos:

$$
\begin{array}{ll}
\text { (25) entraram } & {\left[\tilde{\mathrm{e}}^{\mathrm{n} \mathrm{t}} \text { traru }\right]} \\
\text { puxaram } & {[\text { pu'faru }]}
\end{array}
$$

Já nas produções da Informante 2, as ocorrências com esse tipo de ditongo foram as palavras cuidam e sejam, outras formas e tempos verbais nos quais não houve redução do ditongo. O percentual de 100\% de redução do ditongo /ou్/ em palavras como 'sou' e 
'estou' na fala da Informante 2 pode ser considerado recorrente na língua portuguesa, não dependendo nem de contexto sociolinguístico nem do nível de escolaridade provavelmente a Informante 1 também realizaria a redução desse ditongo.

Por fim, resta-nos analisar o abaixamento das vogais médias. Nesse caso, houve 58 realizações na fala da Informante 1 e 48 na da Informante 2. Consideram-se, porém, apenas os casos em que houve o processo de harmonia vocálica, gerando variantes da chamada "norma padrão" do português brasileiro - ou seja, as formas estigmatizadas ao invés das formas de prestígio, para utilizar o léxico da sociolinguística. Assim, observou-se que a Informante 1 não apresentou nenhuma variação em relação às pronúncias consideradas "padrão" na língua portuguesa; enquanto a Informante 2 realizou 3 variações na leitura de frases dirigidas, que foram:

\begin{tabular}{|c|c|c|c|}
\hline (26) novos & ['novus] & ao invés de & ['novus] \\
\hline Pelé & {$\left[p \varepsilon^{\prime} l \varepsilon\right]$} & ao invés de & [pe'le] \\
\hline fecho & ['fe $\left.\int u\right]$ & ao invés de & ['f $\left.\varepsilon \int u\right]$ \\
\hline
\end{tabular}

A hipótese levantada aqui não é de diferenças referentes ao nível de escolaridade, mas de região. As vogais médias fechadas - e, o - são típicas da região gaúcha, estado de origem da Informante 2 . O fato de que a realização da palavra 'fecho' pela Informante 2 é a considerada "correta" pela gramática tradicional do português seria uma sinalização de que essa variação em nada se relaciona com o nível de escolaridade do falante, mas sim com sua região de origem.

\section{CONSIDERAÇÕES FINAIS}

Os resultados mostram que os processos fonológicos relacionados com acento seguem regras fonológicas como qualquer outro processo, ou seja, não ocorrem aleatoriamente. As variáveis, porém, é que podem ser complexas e de natureza distinta, podendo ser linguísticas ou extra-linguísticas (região, nível de escolaridade, idade, profissão, etc). No caso dos três processos analisados neste artigo, percebe-se influência do nível de escolaridade na ocorrência dos processos estudados: a Informante 2 apresentou a maioria dos processos em sua fala e possui mais baixa escolaridade. Vale ainda apontar outros dados pessoais não descritos anteriormente, como o fato de ser uma dona de casa que não trabalha fora. Esses dados parecem ser fatores extra-linguísticos que podem afetar a realização de tais processos, muitas vezes considerados estigmatizados pela sociedade.

Não depende, porém, apenas de fatores sociais. As pesquisas de Fonologia Gerativa, citadas neste artigo, já mostraram que o contexto linguístico também determina a ocorrência ou não do processo fonológico, por isso a importância de se formular regras consistentes que possam dar conta das variantes possíveis.

No entanto, ressalta-se que o número de sujeitos e de dados analisados neste estudo apenas indicam um comportamento, mas, para se comprovar os resultados apresentados, será necessário aumentar o número de dados e de sujeitos, ampliando a pesquisa, seguindo mais de perto a metodologia encontrada em pesquisas de cunho sociolinguístico. 


\section{REFERÊNCIAS}

ANDRADE D', Ernesto. Temas de fonologia. Lisboa, Colibri, 1994

CAGLIARI, Luiz Carlos. Análise fonológica: introdução à teoria e à prática com especial destaque para o modelo fonêmico. Campinas, SP: Mercado de Letras, 2002. (Coleção ideias sobre a linguagem).

CAMARA JÚNIOR, Joaquim Mattoso. Estrutura da língua portuguesa. 41. ed. Petrópolis, RJ: Vozes, 2008.

COLLISCHONN, Gisela. O acento em Português. In: BISOL, Leda. Introdução a estudos de fonologia do português brasileiro. Porto Alegre, EDIPUCRS, 1999, p. 125-158.

LEPSCHY, Giulio. Fonema e fonologia. Rio de Janeiro: Perspectiva, 1975.

OLIVEIRA, Sidneya Gaspar de; BRENNER, Teresinha de Moraes. Introdução à Fonética e Fonologia da Língua Portuguesa: fundamentação teórica e exercícios para o $3^{\circ}$ grau. Florianópolis: Ed. do Autor, 1988.

SCHANE, Sanford. Fonologia gerativa. Rio de Janeiro: Zahar Editores, 1975.

SILVA, Thais Cristófaro. O processo de monotongação em João Pessoa. In: HORA, D. Estudos sociolinguísticos: perfil de uma comunidade. João Pessoa: ED UFPB, 2004, p. $29-43$.

Exercícios de fonética e fonologia. São Paulo: Contexto, 2003.

Fonética e Fonologia do Português: roteiro de estudos e guia de exercícios.

São Paulo: Contexto, 2002. 


\section{ANEXO I}

\section{CORPUS}

\section{Dados do informante:}
1) Idade:
2) Sexo:
3) Grau de escolaridade:
4) Naturalidade:
5) Descendência:

\section{$\underline{\text { I: Livre }}$}

1) Fale-me onde você nasceu e em quais cidades você já morou.

2) Fale um pouco da sua família (pai, mãe, irmãos, esposo, filhos...).

3) O que você mais gosta de fazer?

4) Quais são seus maiores sonhos?

\section{III: Leitura das frases dirigidas}

Leia as frases abaixo:

1. O fósforo apagou

2. Homem alto

3. Móveis novos

4. Eu fecho a porta

5. Rei Pelé

6. Viagem cansativa

7. Árvore grande

8. Belíssima mulher

9. Menino órfão

10. Xícara de café

11. Doce de abóbora

12. Jogar peteca

13. Bolo de cereja

14. Pizza de brócolis

15. Vôlei de praia 